\title{
Community Pharmacists' Perception of the Relevance of Drug Package Insert as Source of Drug Information in Southwestern Nigeria
}

\author{
Kenechuckwu Diobi, Titilayo O Fakeye* and Rasaq Adisa \\ Department of Clinical Pharmacy \& Pharmacy Administration, Faculty of Pharmacy, University of Ibadan, Ibadan, Nigeria
}

*For correspondence: Email: titilayo.fakeye@yahoo.com; to.fakeye@mail.ui.edu.ng; Tel: +2348052234484

Received: 9 April 2013

Revised accepted: 30 April 2013

\begin{abstract}
Purpose: To evaluate the opinions of community pharmacists on the usefulness and reliability of drug package inserts (DPI) as drug information source, and necessary modifications needed to improve their contents.

Methods: A prospective cross-sectional study using a pretested questionnaire was administered to sixty-one superintendent community pharmacists (CP) across two cities in southwestern Nigeria. Descriptive statistics was used to summarize the data and evaluate respondents' opinion. KruskalWallis test was used to evaluate the rank variables with $p<0.05$ considered significant.

Results: $A$ majority of CP believed that information from DPI was precise and may be helpful in achieving therapeutic success $(n=42 ; 72.8 \%)$. CP believed there is need for the modification of DPI content with respect to patient-related information $(n=52 ; 92.8 \%)$ and health provider-related information ( $n=52 ; 94.5 \%)$, non-uniformity of information on the same generic medicines $(n=31 ; 50.8$ $\%)$, and ambiguity of content ( $n=29 ; 47.5 \%)$. Years of experience in practice significantly influenced respondents' perception of precision and satisfaction with DPI as source of information.

Conclusions: Community pharmacists in southwestern Nigeria believed that a properly modified drug package insert could be a useful and reliable source of drug information in daily practice.
\end{abstract}

Keywords: Community pharmacist, Drug information, Drug package insert

Tropical Journal of Pharmaceutical Research is indexed by Science Citation Index (SciSearch), Scopus, International Pharmaceutical Abstract, Chemical Abstracts, Embase, Index Copernicus, EBSCO, African Index Medicus, JournalSeek, Journal Citation Reports/Science Edition, Directory of Open Access Journals (DOAJ), African Journal Online, Bioline International, Open-J-Gate and Pharmacy Abstracts

\section{INTRODUCTION}

Demand for drug information by health care professionals and patients underscores the need for a reliable, easily accessible and nonexpensive source of information that will aid informed therapeutic decision in the management of diseases. Sources of drug information are numerous and are useful in situations where there is immediate need to counsel patients, choose dosage or check for contraindications. Healthcare professionals make use of different types of drug information sources including primary, secondary and tertiary sources, each with its areas of strength and weakness [1-3].

In resource-limited settings, drug package inserts (DPI) are probably the most readily available source of drug information since it always accompanies prescription and non-prescription medicines. Information from DPI may sometimes not be up-to-date, and inconsistent when compared with other sources of drug information [1-4]. Although written drug information may sometimes cause fear of possible adverse effects, DPI may also be useful in increasing patient's knowledge, compliance and satisfaction 
as well as enable patients have access to information about their medications $[5,6]$. Thus, DPI could be a source of information in developing and developed countries wherever drug information is needed.

Information obtainable in DPI for the same generic medications by different manufacturers are often inconsistent and sometimes conflicting [7-9]. Also, some consumers find the language difficult to comprehend and find it more complex than what is commensurate with an individual's literacy level [10].

The source of drug information is important especially in developing nations such as Nigeria where strict medicine regulation is sometimes lacking. Such countries are at a distinct disadvantage if the practitioners cannot source reliable independent information about medicines. The present study therefore seeks to evaluate and assess the opinions of community pharmacists in southwestern Nigeria on the usefulness, adequacy, reliability and level of satisfaction with DPI as a veritable source of drug information in daily practice. Opinions of respondents on necessary modifications to make DPI a reliable tool for obtaining drug information were also explored.

\section{METHODS}

\section{Study design and population}

This prospective cross-sectional study was carried out among licensed community pharmacists (CP) in two state capital cities (Ibadan and Oshogbo) in southwestern Nigeria using a pre-tested structured questionnaire. At the time of the study in March 2010, 93 premises were registered in the two states with the Pharmacists Council of Nigeria (PCN), the official regulatory body of pharmacy profession and education in Nigeria. Included in the study were CPs who were superintendent pharmacists in charge of registered pharmacies in the two cities. Only pharmacies licensed for the year of study, and who had pharmacists in residence with not less than one-year post full PCN-registration experience were enrolled in the study.

Based on the number of registered community pharmacists at the time of study at a $5 \%$ margin of error, a sample size of 76 was obtained using the Raosoft ${ }^{(\mathrm{R})}$ Sample size calculator [11].

CPs were identified using PCN directory of licensed pharmacists for the year of study. The CPs were then visited in their respective pharmacies and administered the questionnaire. CPs who were not in their premises at the time of visitation were excluded. No two CPs were taken from the same pharmacy. Eighty questionnaires were administered within the study period in the two cities comprising 59 (73.8\%) questionnaires in Ibadan and 21 (26.2\%) in Oshogbo.

\section{Pretest and questionnaire construction}

The questionnaire was pretested among three pharmacists in academia for content validity. Based on the feedback from the validity assessments, some modifications were made to the question format including the replacement of dichotomous "YES/NO" response options with likert scale of five graded response (strongly disagree -1 , disagree -2 , neutral -3 , agree -4 and strongly agree - 5). Also, ambiguous questions were rephrased to convey clear intentions.

Section A obtained information on the demographic characteristics of respondents while section B obtained the opinions of respondents on sources of drug information in daily practice, perceptions on the use of DPI as source of drug information, level of satisfaction with the information obtainable from drug package inserts, and opinion on the probable modifications that will make the DPI a reliable source of drug information. The questionnaires which took between 25 and $30 \mathrm{~min}$ to complete were administered to respondents in their places of practice by the investigators.

Out of the 80 questionnaires administered, 61 (76.3 \%) questionnaires were properly completed and found fit for analysis. The remaining 19 questionnaires were either incompletely filled or contained indefinite responses.

\section{Data analysis}

The data obtained was subjected to analysis using the Statistical Package for the Social Sciences (SPSS) version 17.0. Descriptive statistics were used to summarize the data with median value (50 percentile) used in describing respondents' opinion to particular statements in ordinal scale. Kruskal Wallis test was used to evaluate the association between years of experience in community practice and respondents' opinions in ordinal variables. The level of statistical significance was set at $p<$ 0.05 . 


\section{RESULTS}

The response rate was $76.3 \%$. There were 12 $(19.7 \%)$ respondents with age range of $21-30$ years, $31-40$ years $(n=23,37.7 \%), 41-50$ years $(n=8,13.1 \%)$, while $18(29.5 \%)$ were aged $>50$ years. Thirty one respondents $(50.8 \%)$ had been in practice as community pharmacists for $1-10$ years; nine (14.8\%) for $11-20$ years, while $21(34.4 \%)$ had been in practice for $>20$ years.

Sixty $(98.4 \%)$ respondents made use of drug package inserts in their places of practice, although all the respondents used more than one source of drug information. Other sources of drug information used by respondents in different combinations included the Essential Drug List (EDL, $n=48,78.7 \%$ ), reference books such as British Pharmaceutical Codex and British National Formulary ( $\mathrm{n}=38,62.3 \%)$, peerreviewed pharmacy journals ( $n=38,62.3 \%$ ), Internet-based websites ( $\mathrm{n}=37,60.7 \%)$, textbooks $(n=33,54.1 \%)$, peer-reviewed medical and therapeutic journals $(n=32,52.5$ $\%)$, and encyclopedia ( $\mathrm{n}=16,26.2 \%)$. Drug Information Centers (DICs) were consulted by nine $(14.8 \%)$ of the respondents. Of the sixty (98.4\%) respondents who use DPI; side effects $(\mathrm{n}=48,78.7 \%)$ were the most often sought information from DPI followed by contraindication $(n=46,75.4 \%)$, drug interaction $(n=42,73.8$ $\%)$, and drug dosing $(n=41,67.2 \%)$ in different combinations. However, respondents cited the most common obtainable information from DPI to include side effects $(\mathrm{n}=40,65.6 \%)$, contraindication ( $\mathrm{n}=32,52.5 \%)$, while drug dosing and general product information was reported by 35 respondents $(57.4 \%)$ each. These responses were cited in combinations. The most frequently omitted information from DPI included teratogenicity $(n=21,34.4 \%)$, and pharmaceutical incompatibility ( $\mathrm{n}=16,26.2 \%)$. Details of respondents' opinion on the most often sought information and those that were commonly obtainable are shown in Table 1.

Fifty three $(86.9 \%)$ respondents were usually consulted by patients for clarification on information from DPI, while $52(85.2 \%)$ referred their patients to relevant information in DPI as a follow-up to the counseling on dispensed or recommended medications. Fifty two (85.2\%) respondents believed that DPI has great educative potentials. Other details of respondents' opinions on information to which DPI are most appropriate are shown in Table 2.

Parameters that were significantly influenced by the length of experience in practice included opinion on whether manufacturer's information in DPI is accurate $(p=0.007)$, and whether information from DPI is helpful in achieving therapeutic success $(p=0.047) \quad($ Table 3$)$. Respondents with years of experience above 20 had the highest mean rank (36.35) suggesting that they were the ones who largely agreed that the manufacturer's information in DPI is accurate. The effect of length of experience in practice on the opinion of CP on accuracy and frequency of use of information of DPI is shown in Table 3.

Table 1: Summary of respondents' opinions on the most often sought and obtainable information from drug package inserts (DPI)

\begin{tabular}{lcc}
\hline \multirow{2}{*}{ Variable } & \multicolumn{2}{c}{ Respondents' opinion N (\%) } \\
\cline { 2 - 3 } & $\begin{array}{c}\text { Most often sought } \\
\text { information from DPI }\end{array}$ & $\begin{array}{c}\text { Common obtainable } \\
\text { information from DPI }\end{array}$ \\
\hline Side effects/Adverse reactions & $48(78.7)$ & $40(65.6)$ \\
Contraindication & $46(75.4)$ & $32(52.5)$ \\
Drug interaction & $42(68.9)$ & $25(41.0)$ \\
Drug dosing & $41(67.2)$ & $35(57.4)$ \\
General product information & $35(57.4)$ & $35(57.4)$ \\
Therapeutic efficacy & $32(52.5)$ & $27(44.3)$ \\
Dosing time & $28(45.9)$ & $20(32.8)$ \\
Toxicity & $27(44.3)$ & $17(27.9)$ \\
Teratogenicity & $25(41.0)$ & $15(24.6)$ \\
Pharmaceutical compatibility & $16(26.2)$ & $12(19.7)$ \\
Pharmaceutical identification & $15(24.6)$ & $17(27.9)$ \\
Drug formulation & $12(19.7)$ & $17(27.9)$ \\
Drug choice availability & $10(16.4)$ & $13(21.3)$ \\
\hline
\end{tabular}

* - Responses are in different combinations

DPI - Drug Package Inserts 
Table 2: Respondents' opinions (in ranks) on adequacy and frequency of use of information from DPI

\begin{tabular}{|c|c|c|c|c|c|c|c|}
\hline \multirow[t]{2}{*}{ Variable } & \multicolumn{6}{|c|}{ Respondents' opinion N (\%) } & \multirow[b]{2}{*}{$\begin{array}{c}{ }^{*} K-W \\
p \text {-value }\end{array}$} \\
\hline & Never & Rarely & Sometimes & Often & Always & $\begin{array}{c}\text { Median } \\
\text { value }(50 \\
\text { percentile) }\end{array}$ & \\
\hline $\begin{array}{l}\text { Frequency of patient's consult for } \\
\text { clarification of information from } \\
\text { DPI }(\mathrm{N}=60)\end{array}$ & $2(3.3)$ & $16(26.7)$ & $29(48.3)$ & $11(18.3)$ & $2(3.3)$ & 3 & 0.168 \\
\hline $\begin{array}{l}\text { Frequency of patient's referral to } \\
\text { information supplied in DPI for } \\
\text { follow-up drug usage }\end{array}$ & $8(13.1)$ & $12(19.7)$ & $28(45.9)$ & $11(18.0)$ & $2(3.3)$ & 3 & 0.209 \\
\hline \multicolumn{8}{|l|}{$(\mathrm{N}=61)$} \\
\hline $\begin{array}{l}\text { Educative potential of DPI } \\
\text { information }(N=56)\end{array}$ & $0(0.0)$ & $4(7.1)$ & $24(42.9)$ & $25(44.6)$ & $3(5.4)$ & 3 & 0.528 \\
\hline \multicolumn{8}{|l|}{$\begin{array}{l}\text { Appropriateness of information } \\
\text { from DPI with respect to: }\end{array}$} \\
\hline Drug interaction $(\mathrm{N}=57)$ & $4(7.0)$ & $24(42.1)$ & $13(22.8)$ & $11(19.3)$ & $5(8.8)$ & 3 & 0.957 \\
\hline Dosage $(\mathrm{N}=57)$ & $2(3.5)$ & $0(0.0)$ & $9(15.8)$ & $25(43.9)$ & $21(36.8)$ & 4 & 0.445 \\
\hline Dosing time $(\mathrm{N}=56)$ & $1(1.8)$ & $7(12.5)$ & $16(28.6)$ & $20(35.7)$ & $12(21.4)$ & 4 & 0.494 \\
\hline Duration of action $(\mathrm{N}=57)$ & $2(3.5)$ & $8(14.0)$ & $20(35.1)$ & 19(33.3) & $8(14.0)$ & 3 & 0.974 \\
\hline Side effect $(\mathrm{N}=56)$ & $0(0.0)$ & $1(1.8)$ & $14(25.0)$ & $25(44.6)$ & $16(28.6)$ & 4 & 0.626 \\
\hline Toxicity $(\mathrm{N}=54)$ & $5(9.3)$ & $23(42.6)$ & $15(27.8)$ & $7(13.0)$ & $4(7.4)$ & 2 & 0.328 \\
\hline Over-the-counter medicine & $7(13.5)$ & $25(48.1)$ & $16(30.8)$ & $3(5.8)$ & $1(1.9)$ & 2 & 0.964 \\
\hline
\end{tabular}

${ }^{*} \mathrm{~K}-\mathrm{W}$ - Kruskal Wallis test for respondents' years of experience in practice as community pharmacist; Never $=1$, Rarely $=2$,

Sometimes $=3$, Often = 4, Always $=5, D P I=$ Drug package inserts, $N=$ Number

Table 3: Distribution of respondents' opinion on precision and satisfaction about the information from DPI

\begin{tabular}{|c|c|c|c|c|c|c|c|}
\hline \multirow[t]{2}{*}{ Variable } & \multicolumn{7}{|c|}{ Respondents' opinions N (\%) } \\
\hline & $S D$ & $D$ & $N$ & $A$ & SA & $\begin{array}{c}\text { Median } \\
\text { value (50 } \\
\text { percentile) } \\
\end{array}$ & $\begin{array}{c}K-W \\
p-v a l u e\end{array}$ \\
\hline $\begin{array}{l}\text { Manufacturer's information in } \\
\text { DPI is accurate }(N=58)\end{array}$ & $0(0.0)$ & $\begin{array}{c}10 \\
(17.2)\end{array}$ & $11(19.0)$ & $33(56.9)$ & $4(6.9)$ & 4 & $0.007^{*}$ \\
\hline $\begin{array}{l}\text { Information from DPI is helpful } \\
\text { in achieving therapeutic } \\
\text { success }(\mathrm{N}=58)\end{array}$ & $2(3.4)$ & $4(6.9)$ & $10(17.2)$ & $32(55.2)$ & $10(17.2)$ & 4 & $0.047^{*}$ \\
\hline \multicolumn{8}{|l|}{$\begin{array}{l}\text { Information in DPI that needs } \\
\text { modification with respect to: }\end{array}$} \\
\hline $\begin{array}{l}\text { Patient-related information } \\
(\mathrm{N}=56)\end{array}$ & $3(5.4)$ & $0(0.0)$ & $1(1.8)$ & $32(57.1)$ & $20(35.7)$ & 4 & 0.898 \\
\hline $\begin{array}{l}\text { Healthcare professional-related } \\
\text { information }(\mathrm{N}=55)\end{array}$ & $1(1.8)$ & $0(0.0)$ & $2(3.6)$ & $34(61.8)$ & $18(32.7)$ & 4 & 0.244 \\
\hline $\begin{array}{l}\text { Easy understanding by lay } \\
\text { patient }(\mathrm{N}=54)\end{array}$ & $3(5.6)$ & $2(3.7)$ & $3(5.6)$ & $27(50.0)$ & 19(35.2) & 4 & 0.796 \\
\hline
\end{tabular}

Fifty two $(92.9 \%)$ respondents believed there is a need for modification of information in DPI in respect of patient-related information, and healthcare professional-related information ( $\mathrm{n}=$ $52,94.5 \%$ ), as shown in Table 3. Forty-six (75.4 $\%)$ believed that modifications of information in DPI should include, in different combinations, typography ( $\mathrm{n}=16,26.2 \%$ ), uniformity of information on the same generic with different proprietary names ( $\mathrm{n}=31,50.8 \%$ ), language ( $\mathrm{n}$ $=22,36.1 \%$ ), and clarity of contents ( $n=29$, $47.5 \%$ ) so as to ensure easy comprehension by lay persons. 


\section{DISCUSSION}

Regardless of the years of experience or age or sex of respondents, almost all the community pharmacists who participated in the study relied on drug package inserts either alone or in combination with other drug information sources including primary, secondary and a few tertiary sources. The use of DPI is not limited to developing countries such as Nigeria alone. A study in Sweden showed that most community pharmacists use DPI and standard reference books as sources of drug information especially for drug indication and adverse drug effects [12]. The findings of this study indicated that information most readily obtainable from DPI are side effects or adverse reactions which is probably the most important information required to guide patients on commonly encountered drug use problems, while information on toxicity, teratogenicity, drug interaction, pharmaceutical incompatibilities, and pharmaceutical product identification were not always obtainable.

A study carried out in Saudi Arabia reported that majority of the patients who use DPI always look for information on drug indication and adverse drug effects which were not always available [9]. Though it has been reported that information on side effects from DPI, if accessed by patients, may lead to premature cessation of therapy $[5,6]$, studies have also found that information from DPI may be useful in increasing patient's knowledge, compliance, and satisfaction [6]. However, despite the high proportion of respondents who rely on DPI as a source of drug information; many believed that there is need for improvement in the content of DPI especially in the areas of non-uniformity of information on the same generic medicines, clarity of contents, and improvement of both the patient- and healthcare professional-related information. This finding corroborated earlier studies by Al-Aqeel and Sawalha et al[8,9].

Improvement on DPI typography will improve legibility allowing for easy comprehension and understanding by lay patients, as well as preventing confusion and misinformation. These suggested modifications become necessary in order to make DPI a reliable source of drug information in daily community pharmacist practice, as well as ensuring an informed selfmanagement decision by patients. This is especially important in Nigeria, where prescription-only medicines could easily be obtained without prescriptions, thereby making patients prone to misinterpretation or misunderstanding of the information in the drug package inserts. This study is limited by the fact that it did not differentiate between the DPI for prescription-only medicines and over-the-counter medicines.

\section{CONCLUSION}

Community pharmacists in southwestern Nigeria believe that a drug package insert that has been properly modified for clarity of content and contains pertinent, important and uniform information will be a useful and reliable source of drug information that may be helpful in achieving positive therapeutic decisions.

\section{REFERENCES}

1. Hassali MA, Khan TM, Shafie AA. Use of drug information resources by community pharmacist in Penang, Malaysia. Inform Prim Care 2010; 18(3): 213-216.

2. Cohen JS. Dose discrepancies between the Physician's Desk Reference and the medical literature, and their possible role in the high incidence of doserelated adverse events. Arch Inter Med 2001; 161(7): 957-964.

3. Bangalore S, Kumar S, Messrli F.H. Angiotensinconverting enzyme inhibitor associated cough: deceptive information from the Physicians' Desk Reference. The Am J Med 2010; 123(11): 10161030.

4. Cohen JS. Adverse drug effects, compliance, and initial doses of antihypertensive drugs recommended by the Joint National Committee vs the Physicians' Desk Reference. Arch Intern Med 2001; 161(6): 880-885.

5. Vander Stichele $\mathrm{RH}$, Van Haecht $\mathrm{CH}$, Braem $\mathrm{MD}$, Bogaert MC. Attitude of the public toward technical package inserts for medication information in Belgium. DICP 1991; 25(9): 1002-1006.

6. Shrank WH, Avorn J. Educating patients about their medication: the potentials and limitations of written drug information. Health Aff 2007; 26(3): 731-740.

7. Raynor DK, Svarstad B, Knapp $P$, Rogers MB, Koo M, Krass I, Silcock J. Consumer medication information in the United States, Europe and Australia: a comparative evaluation. J Am Pharm Assoc (2003) 2007; 47(6): 717-721.

8. Sawalha A, Sweileh N, Zyoud Sh, Jabi S. Comparative analysis of patient package inserts of local and imported anti-infective agents in Palestine. Libyan $J$ Med 2008; 3(4): 181-185.

9. Al-Aqeel SA. Evaluation of medication package inserts in Saudi Arabia. Drug Health Patient Saf 2012; 4: 33-38.

10. Davis TC, Wolf MS, Bass PF $3^{\text {rd }}$, Thompson JA, Tilson $\mathrm{HH}$, Neuberger $\mathrm{M}$, Parker RM. Literacy and misunderstanding prescription drug labels. Ann Intern Med 2006; 145(12): 887-894.

11. Raosoft ${ }^{(R)}$ Sample size calculator. www.raosoft.com/samplesize.html. Accessed on the 15th March, 2010.

12. Zehnder S, Beutler M, Brupaccher R, Ehrenhofer $T$, Hersberger KE. Needs of drug information sources in community pharmacies: a questionnaire based survey in German-based Switzerland. Pharm World Sci 2004; 26(4): 197-202. 